\title{
Prevalence of Pediculus humanus capitis in a school of low socio-economy area in Rampur (U.P), India
}

\author{
Archna Rashmi*, Nayanci Bansal, Gaurav Arya and Aftab Ahmad \\ Department of Zoology, Government Raza Postgraduate College, Rampur- 244901(U.P), INDIA \\ *Corresponding author. E-mail: akscsir@ rediff mail.com
}

\begin{abstract}
The prevalence of head louse Pediculus humanus capitis on the school children of a low socio-economy area of Rampur, India was found to be $56 \%(n=300)$. Female children appeared lousier. However, the hygienic condition and their density appeared to have negligible effect on head louse.
\end{abstract}

Keywords: Ectoparasite, Phthiraptera, Head louse.

\section{INTRODUCTION}

Human head louse, Pediculus humanus capitis is known to transmit typhus fever, relapsing fever and trench fever, especially in soldiers on the battlefronts, in the refugees during famine and in stricken populations. The prevalence and infestation intensity of human head louse have been recorded from time to time (Fan et al., 1991, 1997, 1999a, 1999b; Castro et al., 1994; Chung et al., 1998; Borges et al., 2002; Reinhard et al., 2003; Karatas et al., 2004; Tatman-Otkum et al., 2005; Jaing et al., 2007 and Hodjati et al.,2008). Present report deals with the prevalence of head lice in the district Rampur, (U.P), India.

\section{MATERIALS AND METHODS}

The study was conducted on school children of a low socio-economy (labors, rikshawpullers etc. earning on 50-95 thousand per annum) area in Rampur from first weak of Dec.2007. The children of each grade were asked to line up according to sex. The hair of each child was visually examined by naked eye (gross examination) paying special attention to the back of the head, a preferred nesting area of lice. The infested children were gathered together and were given fine- toothed comb, a small homeopathic tube containing $70 \%$ alcohol, a pencil, a label, and a blank paper ( 42 X $29.5 \mathrm{~cm})$. The children were asked to write their name, grade, age, and name of the school on the paper, which was placed on the table. After combing their own hair with the fine-toothed comb for 12-15 minutes, the nymphs and adults collected from the paper were placed in the small bottle. The data was used for recording the prevalence, mean intensity, sample mean abundance, correlation with age and prevalence. The goodness of fit between observed and expected frequencies were determined by $\mathrm{X}^{2}$ test.

\section{RESULTS}

Fifty six Percent (56\%) of the examined school children carried the head louse, $P$. humanus capitis. A total of 253 lice (67 male, 81 female, 31 first Instars, 21 second Instars, 53 third Instars) were recovered. Prevalence on male and female children was $11.7 \%$ and $44.7 \%$, respectively significantly higher in females, mean intensity is 1.5 .Out of 169 school children 98 were below 9 years and remaining 71 were above 9 years. So, mean intensities were found to be 1.3 and 1.6 respectively.

Fifty-three of the school children aging below 9 years had normal hair while remaining 38 carried dense hair. On the other hand, 32 students aging above 9 years bore normal hair while remaining were 46 more hairy. Mean intensity of the head lice on the four groups appears similar. $\left(\mathrm{X}^{2}=1.47 ; \mathrm{df}=1\right)$. As for as the hygienic conditions are concerned out of the 71 students aging below 9 years, 15 appeared cleaner, 28 normal and remaining 28 dirty. Likewise, out of 98 children aging above 9 years 33 appeared cleaner, 36 normal and 29 dirty. There was an insignificant difference in the mean intensities of the lice on 6 categories $\left(\mathrm{X}^{2}=0.0764\right.$; $\left.\mathrm{df}=2\right)$ as per information provide by the children out of the 103 aging below 9 years 24 bathed every day, 35 three to four time per week and 44 once in a week (during winter). On the other hand out of 66 children aging above 9 years reportedly bathed regularly and remaining three to four time per week. Mean intensities of the head louse did not differ significantly, in a four set categories. $\left(X^{2}=0.17 ; d f=2\right)$. An attempt has also been made to record the extent of correlation between the age of school children $(3,4,5,6,7,8,9,10,11,12,13)$ and the mean intensities of head lice recovered in concerned the value of Karl Pearson's coefficient of correlation ( $r=$ -0.06181 ) was found to insignificant.

\section{DISCUSSION}

There are several reports on the prevalence of head louse $P$. humanus capitis among school childrens of Tiwan, Argentina, Brazil, Peru, Edirne, Hualien County, Aydm, 
(Fan et al., 1991, 1997, 1999a, 1999b; Castro et al., 1994; Chung et al., 1998; Borges et al., 2002; Reinhard et al., 2003; Karatas et al., 2004; Tatman-Otkum et al., 2005; and Jaing et al., 2007). Survey of literature indicates that prevalence of head louse varied from $7 \%$ to $59 \%$ in different parts of World. During present studies, prevalence of head louse in 300 school children was recorded in a rural area of Rampur (U.P) India. During present study the prevalence of school children was found will be $56.2 \%$. Prevalence of head lice on school girls $(44.7 \%)$ was distinctly higher than school boys (11.6\%). Most of the earlier workers have also found similar results. Prevalence on younger children (below 9 years) was significantly higher $\left(\mathrm{X}^{2}=1.03 ; \mathrm{df}=1\right)$. Like wise children bearing dense hair appeared to be less lousy $\left(\mathrm{X}^{2}=1.47 ; \mathrm{df}=2\right.$ significantly). The hygienic condition did not seem to any affect, as there was no significant difference in the prevalence of lice on clean, normal, and dirty school children. Likewise no significant difference was noted in the head lice prevalence of school children taken both once a week, three to four time per week and daily $\left(\mathrm{X}^{2}=1.7 ; \mathrm{df}=2\right)$.

\section{ACKNOWLEDGEMENTS}

The authors are thankful to the Principal, Govt. Raza P.G. College, Rampur (U.P) India for providing laboratory facilities.

\section{REFERENCES}

Borges, R. and Mendes, J. (2002). Epidemiological aspects of head lice in children attending day care centers, urban and rural schools in uberlandia, Central Brazil. Member Inst Oswaldo Cruz, Rio de Janeiro, 97(2): 189-192.

Castro, D.D., Abrahamovich, H.A., Cicchino, A.C., Rigoni, A.M., Raftaeli, C. and Barrio, A.D. (1994). Prevalence and seasonal variation of Pediculosis capitis in the population under sixteen year of age of the health region of Buenos Aires, Argentina. Revista Saude Publication, 28(4): 295-9.

Chung, W.C., Fan, C.K., Chen, E.R. and Fan, P.C. (1998). Studies on Pediculosis control among school children in Taiwan and affshore areas. Chinese Journal of Parasitology, 11: $19-36$.
Fan, P.C., Chung, W.C., Kuo, C.L., Hsu, H.M. and Chow, C.H. (1991). Present status of head louse (Pediculus capitis) infestation among school children in Yunlin County Taiwan. Kaohsiung. Journal of Medical Science, 7: 151-159.

Fan, P.C., Chung, W.C., Fan, C.K., Yen, C.W. and Hung, P. (1997). Prevalence and chemotherapy of Pediculus capitis infestation among school children in mountainous and plain areas of Pingtung, Kaohsiung, Yunalin and Ilan counties, Taiwan. Chinese Journal of Parasitology, 10: 25-39.

Fan, P.C., Chung, W.C. and Fan, C.K. (1999a). Studies of Pediculus capitis infestations among school children in Taiwan and offshore islands with a special emphasize on evaluation of Pediculosis control programm in the past years. Chinese Journal of Parasitology, 12: 71-87.

Fan, P.C., Chung, W.C., Fan, C.K., Hung, P. and Yen, C.W. (1999b). Prevalence and tretment of Pediculus capitis infestation among aboriginal school children in Northern Taiwan. Kaohsiung. Journal of Medical Science, 15: 209217.

Hodjati, M.H., Mousavi, N., and Mousavi, M. (2008). Head lice infestation in school children of a low socio-economy area of Tabriz city, Iran. Journal of Biotechnology, 7(13): 2292-2294.

Jaing, D.D.S. and Chen, S.C. (2007). An investigation on Prevalence and awareness of elementary school students infested with head lice in Hualien County. Taiwan Epidemiology Bull., 231(31): 58-82.

Karatas, E., Sari, C., Eratabaklar, H., Okyay, P. and Ertug, S. (2004). The Prevalence of Pediculus capitis in students of three primary schools in Aydm. Turkiye Parazitoloji Dergisi, 28(1): 38-41.

Reinhard, K. and Buikstra, J. (2003). Louse infestation of the chiribaya culture, Southern Peru: variation in Pervslence by age and sex. Member Inst Oswaldo Cruz, Rio de Janeiro, 98(1): 173-179.

Tatman-Otkun M, Gurcan S, Ozer B, Ertem A, Sakru N and Otkun M. (2005). The prevalence of Pediculus humanus capitis and Tinea capitis among elementary school students in Edirne. Trakya University Tip Fak Derg, 22(2): 82-87. 